\title{
DEDICATION: To Wim Mook
}

\section{Bravo, Wim!}

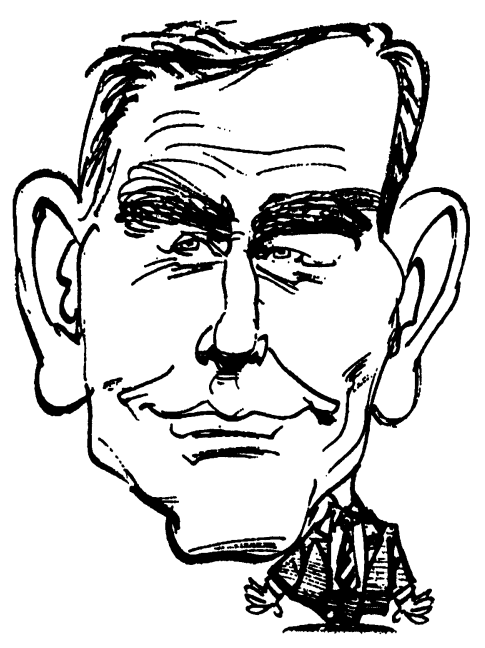

Thanks, Wim, for all you have done. Especially for this 16th Radiocarbon Conference.

We in Tucson and your Groningen colleagues have dedicated this record of the conference to you, the primary conference host. A conference such as this one is many things to many people. In addition to embracing good science, seeing old friends and meeting new ones, we saw in this conference a clear imprint of the renowned Dutch organizational skills as well as the characteristic regional sense of humor.

Of course, others have hosted very successful and well-received radiocarbon conferences without such special recognition, and it is not this journal's intent to set a precedent. However, as the conference coincided with your retirement, we see this dedication as a special case, emblematic of a career achievement award. The radiocarbon community contains many high-achiever specialists, but few high-achiever generalists, such as you.

As you and I and a few others know, the work is far from over on the evening of the final day of the conference. This post-conference editorial work is at least as critical to the quality of the final product as is the initial planning. You and Hans took very active roles in the reviewing and editing process. Your extensive experience and knowledge in carbon geochemistry of the atmospheric, oceanic and terrestrial environments, your active applications of radiocarbon to geology, hydrology and archaeology, as well as your practical experience in the physics and technology of radiocarbon dating, served you well during all stages, and really shows here. I am sure that everyone else will agree that the quality of the final product strongly reflects your care and efforts.

Austin Long

May 1998 